\title{
IGF1R blockade with ganitumab results in systemic effects on the GH-IGF axis in mice
}

\section{Gordon Moody, Pedro J Beltran, Petia Mitchell, Elaina Cajulis, Young-Ah Chung, David Hwang', Richard Kendall, Robert Radinsky, Pinchas Cohen² and Frank J Calzone}

Oncology Research Therapeutic Area, Amgen, Inc., One Amgen Center Drive, Thousand Oaks, California 91320, USA ${ }^{1}$ David Geffen School of Medicine, Los Angeles, California, USA

${ }^{2}$ USC Davis School of Gerontology, Los Angeles, California, USA
Correspondence should be addressed to G Moody

Email gmoody@amgen.com

\begin{abstract}
Ganitumab is a fully human MAB to the human type 1 IGF receptor (IGF1R). Binding assays showed that ganitumab recognized murine IGF1R with sub-nanomolar affinity $\left(K_{\mathrm{D}}=0.22 \mathrm{nM}\right)$ and inhibited the interaction of murine IGF1R with IGF1 and IGF2. Ganitumab inhibited IGF1-induced activation of IGF1R in murine lungs and CT26 murine colon carcinoma cells and tumors. Addition of ganitumab to 5 -fluorouracil resulted in enhanced inhibition of tumor growth in the CT26 model. Pharmacological intervention with ganitumab in naïve nude mice resulted in a number of physiological changes described previously in animals with targeted deletions of $I g f 1$ and $I g f 1 r$, including inhibition of weight gain, reduced glucose tolerance and significant increase in serum levels of GH, IGF1 and IGFBP3. Flow cytometric analysis identified GR1/CD11b-positive cells as the highest IGF1R-expressing cells in murine peripheral blood. Administration of ganitumab led to a dose-dependent, reversible decrease in the number of peripheral neutrophils with no effect on erythrocytes or platelets. These findings indicate that acute IGF availability for its receptor plays a critical role in physiological growth, glucose metabolism and neutrophil physiology and support the presence of a pituitary IGF1R-driven negative feedback loop that tightly regulates serum IGF1 levels through Gh signaling.
\end{abstract}
Key Words
- ganitumab
- IGF1R
- IGFBP3
- receptor pituitary
- human
- murine

\section{Introduction}

The type 1 insulin-like growth factor receptor (IGF1R) is a tyrosine kinase receptor that mediates the positive effects of its ligands, IGF1 and IGF2, on cell growth and survival (Baserga et al. 1997). IGF1 functions as a hormone and paracrine growth factor and is a key component of both the pre- and postnatal physiological mechanisms controlling organ size and tissue homeostasis (Gallagher \& LeRoith 2011, Pollak 2012). IGF2 exerts most of its activity during embryonic development and binds to IGF1R and IGF2R as well as to the insulin-receptor splice variant A (IR-A; Frasca et al. 1999).

The role of the ligands and receptors of the insulin/IGF signaling pathway in mouse development and adult physiology has been the subject of an elegant series of targeted genetic analyses. In LID (liver-derived Igf1 gene-deleted mouse model) mice, where IGF1 levels were reduced by 75\% (Sjogren et al. 1999, Yakar et al. 1999), postnatal growth and development were

Published by Bioscientifica Ltd 
essentially normal; however, the mice displayed insulin resistance associated with a fourfold increase in serum growth hormone (GH) levels (Yakar et al. 2001). LID mice also had reduced splenic cellularity with a decrease in the number of myeloid progenitors, but bone marrow cellularity and immune parameters (B and $\mathrm{T}$ cells) were unaffected, suggesting a role for circulating IGF1 in transition or survival of myeloid progenitors in the spleen (Welniak et al. 2004). In homozygous $\operatorname{Ig} f 1^{(-/-)}$ mice, birth weight was about $60 \%$ of normal mice, and the weight of animals that survived was only $30 \%$ of their normal adult littermates (Baker et al. 1993). Mice with homozygous null mutations in Igflr had normal embryonic development but died soon after birth ( $45 \%$ normal weight), whereas heterozygous mice had normal growth up to the natural weaning period followed by a significant reduction in weight gain and development of insulin resistance (Holzenberger et al. 2003). Elevations in pituitary GH and IGF1 levels have been observed in heterozygous $I g f 1 r^{(+/-)}$mice (Holzenberger et al. 2003), and elevations in GH levels were evident in mice, where circulating IGF1 levels were reduced by whole-animal (Liu \& LeRoith 1999) and liver-specific Igf1 gene disruption (Sjogren et al. 1999, Naranjo et al. 2002), supporting the existence of a negative feedback loop where circulating GH/IGF1 levels regulate their own synthesis through IGF1R signaling in the pituitary gland.

We have shown previously that ganitumab, a fully human MAB to IGF1R, inhibits the activation of human IGF1R and IGF1R-insulin receptor (IR) hybrids without cross-reacting with the IR (Beltran et al. 2009, 2011). In addition, we have demonstrated that targeting a specific epitope in the cysteine-rich (CR) domain of IGF1R results in subtle but distinct differences in the molecular profile of ganitumab when compared with IGF1R antibodies targeting different domains (Calzone et al. 2013). A number of clinical trials evaluating ganitumab and other therapeutic anti-IGF1R antibodies for the treatment of human cancer have been completed (Rodon et al. 2008, Yuen \& Macaulay 2008, Heidegger et al. 2011). Though the optimal context and combination strategy for positioning a clinical IGF1R antibody remain to be elucidated (Guha 2013), data from these studies continue to reveal new roles for IGF1R in physiology and disease; therefore, it is important to develop animal models that help us understand the consequences of inhibiting IGF1R in biological systems. In this study, we demonstrate that, in addition to its interaction with human IGF1R, ganitumab reacts with and inhibits murine IGF1R, providing a unique opportunity to examine the effects of ganitumab on the somatotropic GH-IGF1 axis and tissue homeostasis in mice.

\section{Materials and methods}

\section{Animals}

CD1 nude mice (Charles River Laboratories, Hollister, CA, USA) or athymic nude mice (Harlan Laboratories, Inc.) were housed in sterile cages, five per cage. The laboratory housing the cages met all AAALAC specifications. All experimental procedures were performed in accordance with the IACUC and USDA rules and regulations.

\section{Cell lines and reagents}

The murine colon carcinoma cell line, CT26, was purchased from the American Type Culture Collection (ATCC, Manassas, VA, USA) and maintained in RPMI supplemented with $10 \%$ FBS. Ganitumab was produced by Amgen, Inc. (Thousand Oaks, CA, USA). A human IgG1 raised against streptavidin (Amgen, Inc.) was used as a nonspecific control for ganitumab. IGF1 and IGF2 were obtained from Sigma. Ruthenium-labeled IGF1 and IGF2 were generated at Amgen, Inc. and 5-fluorouracil was acquired from Sandoz (Basel, Switzerland).

The mIGF1R extracellular domain (ECD) (amino acid residues 31-941) was fused to a mIgG1 Fc-coding region (Bass et al. 1996) to create mIGF1R(ECD)-mFc. The fusion protein was expressed in $\mathrm{CHO}$ cells and purified by recombinant Protein A Sepharose (GE Healthcare, Pasandena, CA, USA) affinity chromatography.

\section{Characterization of ganitumab cross-reactivity by Biacore solution equilibrium binding assays}

The Biacore equilibrium method was used to determine the equilibrium binding constant $\left(K_{\mathrm{D}}\right)$ of ganitumab for mIGF1R(ECD)-mFc as described previously (Beltran et al. 2009). The $K_{\mathrm{D}}$ was obtained from nonlinear regression of the competition curves using an n-curve one-site homogeneous binding model (KinExA Pro software, Sapidyne Instruments, Inc., Boise, ID, USA).

An ORIGEN binding assay was used to determine the effect of ganitumab on human IGF1 and IGF2 binding to murine IGF1R(ECD)-mFc using procedures provided by the manufacturer (IGEN, Inc., Gaithersburg, MD, USA). Dynal M450 paramagnetic beads coated with sheep antimouse IgG were used as the solid support phase for the

Published by Bioscientifica Ltd 
IGF1R(ECD)-mFc. Each assay contained PBS, 0.05\% Tween 20 (Mallinckrodt, St. Louis, MO, USA), 0.1\% BSA, $50 \mathrm{ng}$ receptor loaded onto $1 \times 10^{6} \mathrm{M} 450$ beads, $0.25 \mathrm{nM}$ ruthenium-labeled IGF1 or $0.5 \mathrm{nM}$ ruthenium-labeled IGF2, $10^{-6}-10^{-11} \mathrm{M}$ ganitumab or rituximab and $10^{-11_{-}}$ $10^{-6}$ M IGF1 or IGF2 in a volume of $100 \mu$ l assay buffer. After incubation at room temperature in the dark for $2 \mathrm{~h}$, an M384 instrument (Roche Ltd) was used to remove free ruthenium-labeled ligand and to determine the amount of receptor-bound ligand.

\section{Inhibition of murine IGF1R autophosphorylation}

Serum-starved CT26 murine colon carcinoma cells were pretreated with increasing concentrations of ganitumab or hIgG1 (500-0.032 nM) for $10 \mathrm{~min}$ before addition of $2 \mathrm{nM}$ IGF1 for $15 \mathrm{~min}$. Murine IGF1R was immunoprecipitated with $5 \mu \mathrm{g}$ human anti-mIGF1R MAB LC2 (Amgen, Inc.) and immunoblotted with anti-phosphorylated IGF1R/ phosphorylated IR antibody (Cell Signaling Technologies, Inc., Danvers, MA, USA) and anti-IGF1R $\beta$ antibody C-20 (Santa Cruz Biotechnology, Inc.) to detect phosphorylated and total mIGF1R levels respectively. The specificity of all antibodies was confirmed using genetically engineered cell lines and western blotting.

\section{In vivo pharmacodynamic and efficacy studies}

Naïve and tumor-bearing mice were used to examine the effects of ganitumab on levels of phospho- and total mouse IGF1R in vivo. One million CT26 cells were injected subcutaneously into female athymic nude mice. For pharmacodynamic assays, when the average tumor size reached $300-450 \mathrm{~mm}^{3}$, mice were randomly divided into four groups ( $n=3$ per group). Two groups of mice were pretreated with $1 \mathrm{mg}$ ganitumab and two with $1 \mathrm{mg}$ hIgG1 by i.p. injection. After $6 \mathrm{~h}$, one ganitumab group and one hIgG1 group were administered with human IGF1 $(5 \mu \mathrm{g})$ by i.v. injection. Control groups were administered with $1 \times$ PBS. Tumors were collected $15 \mathrm{~min}$ post IGF1 challenge and snap frozen in liquid nitrogen. The same procedure was followed for collection of lung tissue from naïve mice $(n=2)$. For efficacy studies, $250 \mathrm{~mm}^{3}$ tumors were divided into four groups $(n=10)$. Mice were dosed with either ganitumab or hIgG1 twice per week ( $1 \mathrm{mg}$ for the first dose and $300 \mu \mathrm{g}$ for the following doses), 5-fluorouracil $(40 \mathrm{mg} / \mathrm{kg}$ ) for 5 days or the combination of both agents. Treatment was continued for the length of the experiment. Tumor volumes and body weights were measured twice per week using calipers and an analytical scale respectively.
Tumor growth inhibition was expressed relative to the initial and final mean tumor volumes of the control group.

Lysates of lungs and CT26 tumors (mIGF1R) were analyzed by immunoprecipitation using $5 \mu \mathrm{g}$ anti-IGF1R mAb L2C and Protein G Sepharose (GE Healthcare) and by western blotting using anti-phospho-IGF1R/ phospho-IR antibody (Cell Signaling Technologies, Inc.) and sheep anti-mouse-HRP (GE Healthcare). An anti- $\beta$ tubulin antibody (Sigma) was used to probe the nonimmunoprecipitated lysate to normalize the i.p. signal. Western blots were developed using Pierce Supersignal Pico (Pierce, Rockford, IL, USA) and images were captured with the VersaDoc imaging system (Bio-Rad). Densitometry was performed on blot images using Quantity One software (Bio-Rad).

\section{Measurement of IGF1R in murine peripheral blood}

Mouse whole blood $(0.5 \mathrm{ml})$ was harvested from naïve female athymic nude mice by cardiac puncture into EDTA/heparin-coated capillary tubes. Red blood cells were lysed, and white blood cells were stained for flow cytometry with ganitumab followed by staining with goat anti-hIgGFITC, anti-CD11b-PE and anti-GR-1-APC (allophycocyanin, BD Biosciences, San Jose, CA, USA). Events were captured using FACSCalibur and analyzed using CellQuest software (BD Biosciences).

\section{Measurement of peripheral neutrophils, platelets and erythrocytes}

In all experiments, $150 \mu$ l of blood were collected from anesthetized animals by retro-orbital bleeding using heparin-coated glass capillary tubes. Blood was collected into Microtainer tubes with EDTA and diluted 1:1 with $0.1 \%$ BSA in PBS. Peripheral blood cell types were quantified using the ADVIA120 Hematology System (Siemens Healthcare Diagnostics, Los Angeles, CA, USA).

The effects of ganitumab on peripheral neutrophils were assessed in eight female athymic nude mice dosed intraperitoneally with hIgG1 or ganitumab (300 $\mu \mathrm{g} / \mathrm{dose})$ twice per week for a total of five doses. Peripheral neutrophils were quantified once per week for 7 weeks.

The effects of ganitumab on the number of peripheral neutrophils in the presence of mGCSF were also determined in female athymic nude mice. Five mice were dosed with $300 \mu \mathrm{g}$ ganitumab or hIgG1 (day 1) followed by two doses (once daily, days 2 and 3 ) of mGCSF (2.5 $\mu$ g s.c.) or PBS (s.c.). The 3-day dosing cycle was repeated six times for 3 weeks. The number of neutrophils was determined

Published by Bioscientifica Ltd 
once per week on days 6, 13 and 20 after the start of dosing using the ADVIA120 Hematology System.

\section{Glucose tolerance test}

Thirty male athymic nude mice were dosed by i.p. injection with ganitumab or hIgG1 $(300 \mu \mathrm{g} /$ dose) twice weekly for 4 weeks. Twenty-four hours after the last dose, mice were fasted for $16 \mathrm{~h}$. Twenty-five mice in each group were then challenged with an i.p. injection of $25 \%$ glucose $(2 \mathrm{~g} / \mathrm{kg}$ ) for $15,30,60,90$ or $120 \mathrm{~min}$ (five mice per time point); five mice in each group were not challenged with glucose to establish basal blood glucose levels. At each time point, mice were anesthetized using isoflurane, and blood was drawn by cardiac puncture for serum analysis using the AU400 glucose analyzer (Olympus Life and Material Science Europa, Clare, Ireland). In pilot studies, it was found that the use of different cohorts per time point produced the most consistent and least variable results when blood glucose was measured.

\section{Inhibition of weight gain by ganitumab}

Total body weight gain of naïve, adolescent athymic female mice was measured during a 28-day ganitumab treatment period. Mice were divided into groups based on the body weight (ten animals/group; average weight, $19.6 \mathrm{~g}$ ) and treated with either ganitumab (80 or $300 \mu \mathrm{g} /$ dose) or hIgG1 (300 $\mu \mathrm{g} /$ dose) twice weekly by i.p. injection. The weight was measured twice weekly using an analytical scale.

\section{Measurement of mouse serum markers (IGF1, mIGFBPs and $\mathrm{mGH}$ )}

To determine the effect of ganitumab on the serum levels of mIGF1, mIGFBPs and mGH, 7-week old, athymic nude female mice (15 per group) were dosed by i.p. injection with either hIgG1 or ganitumab (300 $\mu \mathrm{g} /$ dose) twice per week for 30 days. Fifteen mice per group were killed on day 30 for serum analysis. The levels of mIGF1, mIGFBP1, mIGFBP2, mIGFBP3 and mALS were measured using mouse-specific ELISAs (Anzo et al. 2008, Hwang et al. 2008, Lee et al. 2010). The assay specifications were as follows: mIGF1 - sensitivity $0.1 \mathrm{ng} / \mathrm{ml}$, no cross-reactivity with mIGF2 and intra-assay and inter-assay coefficient of variation $(\mathrm{CV})$ values - $<10 \%$ (range $1-10 \mathrm{ng} / \mathrm{ml}$ ); mIGFBP1, mIGFBP2 and mIGFBP3 - sensitivity $0.2 \mathrm{ng} / \mathrm{ml}$ and intra-assay and inter-assay $\mathrm{CV}$ values $-<6$ and $<8 \%$ respectively (range 1-6 ng/ml) and mALS - sensitivity
$1 \mathrm{ng} / \mathrm{ml}$ and intra-assay and inter-assay CV values $-<10 \%$ (range 10-60 ng/ml). Serum mGH levels were determined using an enzyme immunoassay (EIA) kit (ALPCO, Salem, $\mathrm{NH}$, USA) according to the manufacturer's instructions (detection limit: $0.5 \mathrm{ng} / \mathrm{ml}$; intra-assay and inter-assay CV values: $<10$ and $<14 \%$ respectively).

\section{Statistical analysis}

Statistical analysis: in the xenograft experiment, the effect of the combination treatment was compared with that of treatment with either agent using repeated-measures ANOVA (RMANOVA). In the body weight experiment, RMANOVA with Fisher's protected least significant difference (PLSD) post hoc was used. For the pharmacodynamic assays (mouse lung pharmacodynamic assay, CT26 tumor pharmacodynamic assay, $\mathrm{CBC}$ analysis and glucose tolerance test), one-way ANOVA with Scheffe's post hoc test was used. Power calculations: for the body weight experiment, ten mice per group were used based on historical body weights to detect differences between 5\% $(n=17)$ and $10 \%(n=5)$ in mouse body weight in the ganitumab-treated cohort. For the glucose tolerance test, five mice per time point were chosen based on a pilot study to detect $\sim 30 \%$ change in glucose levels between the ganitumab-treated and control-treated mice at each time point. For the in vivo phosphorylation assay using CT26 tumors, values from in vitro PIGF1R experiment were used to predict changes in pIGF1R in vivo. For this experiment, three tumor samples would allow detection of $20 \%$ difference in pIGF1R levels in mice.

\section{Results}

\section{Ganitumab binds mIGF1R and inhibits IGF1- and IGF2-mediated activation of mIGF1R}

Ganitumab bound to purified mIGF1R(ECD)-mFc with a $K_{\mathrm{D}}$ of $0.22 \pm 0.05 \mathrm{nM}$ (Fig. 1A) and potently inhibited the binding of hIGF1 and hIGF2 to mIGF1R(ECD)-mFc with Ki values of $1.9 \pm 0.04$ and $1.2 \pm 0.19 \mathrm{nM}$ respectively (Fig. 1B). Ganitumab also inhibited IGF1-induced autophosphorylation of mIGF1R in CT26 murine colon carcinoma cells in a dose-dependent manner (Fig. 1C) at similar concentrations as those observed in human cell lines (Beltran et al. 2009). No inhibition of ligand-induced autophosphorylation was observed using hIgG1, and ganitumab alone had no agonistic activity in CT26 cells (Fig. 1C).

Published by Bioscientifica Ltd 

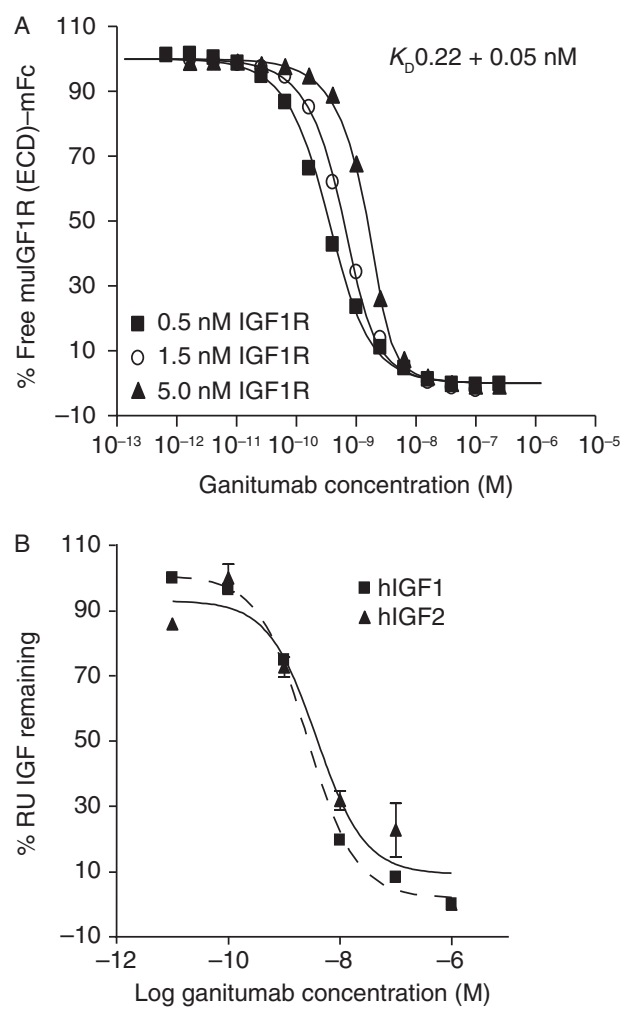

C

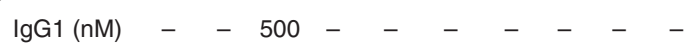
$\begin{array}{lllllllllll}\text { Ganitumab (nM) } & - & 500 & - & 500 & 100 & 20 & 4 & 0.8 & 0.16 & 0.032\end{array}$ IGF1 (2 nM) - -++++++++ pIGF1R

Figure 1

Interaction of ganitumab with mIGF1R. (A) Ganitumab $K_{\mathrm{D}}$ measurement. Binding affinity of ganitumab to mIGF1R(ECD)-mFc measured using the Biacore equilibrium method. (B) Ganitumab blockade of hIGF1 and hIGF2 binding. A binding assay with $\mathrm{mIGF} 1 \mathrm{R}(\mathrm{ECD})-\mathrm{mFc}$ was used to evaluate ganitumab blockade of ruthenium-labeled hIGF1 and hIGF2 $(n=2$, mean \pm s.D.). (C) Ganitumab inhibition of mIGF1R phosphorylation. Serum-starved CT26 cells were pretreated with increasing concentrations of ganitumab before challenge with 2 nM IGF1 for 15 min. IGF1R phosphorylation was determined by immunoprecipitation and western blotting. pIGF1R, phosphorylated IGF1R; RU, relative units.

\section{Ganitumab inhibits IGF1-induced activation of mIGF1R in murine lungs and syngeneic CT26 tumors}

The pharmacological activity of ganitumab in mice was tested using an IGF1 challenge pharmacodynamic model described previously (Beltran et al. 2009). Treatment of mice with IGF1 led to an increase in the levels of phosphorylated mIGF1R in murine lungs (Fig. 2A). Mouse lungs were chosen for the PD assay because they displayed the highest level of IGF1R activation of any organ in the mouse upon challenge with IGF1. The IGF1-induced activation of mIGF1R was completely inhibited when mice were pretreated with ganitumab (1 mg/dose), but not when mice were pretreated with hIgG1 (Fig. 2A). The low levels of basal phosphorylated mIGF1R did not allow detection of any further inhibition by ganitumab (Fig. 2A). The effective dose of ganitumab in a single-dose pharmacodynamic study was described previously (Beltran et al. 2009).

Intravenously administered IGF1 induced an approximate fivefold increase in the levels of phosphorylated mIGF1R in CT26 tumors (Fig. 2B). Pretreatment with ganitumab (1 mg/dose) completely inhibited this stimulation and led to degradation ( $>70 \%$ ) of total mIGF1R both in the absence and in the presence of IGF1 (Fig. 2B). The extensive receptor downregulation observed following ganitumab treatment prevented the accurate characterization of changes in the basal pIGF1R levels after ganitumab treatment.

Ganitumab treatment of CT26 established xenografts resulted in consistent tumor growth inhibition of $\sim 30 \%$. However, combining ganitumab with 5-fluorouracil resulted in $\sim 80 \%$ tumor growth inhibition (Fig. 2C). The degree of tumor growth inhibition achieved in combination with 5-fluorouracil was statistically better than 5-fluorouracil alone $(P<0.001)$.

\section{Ganitumab treatment reduces peripheral blood neutrophils}

Using flow cytometric analysis, ganitumab detected high levels of IGF1R in murine (GR1+/CD11b+) cells (Fig. 3A). We therefore sought to determine whether the loss of IGF1R activity in response to ganitumab treatment could generate a myeloid lineage phenotype as shown previously (Welniak et al. 2004). Mice treated with ganitumab (300 $\mu \mathrm{g} /$ dose) for 2 weeks displayed a marked reduction (up to 50\%) in the number of peripheral neutrophils when compared with hIgG1 controls (Fig. 3B, $P<0.01$ ) with a maximal reduction on day 17 , after reaching steady-state serum levels based on the previous pharmacokinetic studies using this dosing regimen (Beltran et al. 2009). The effect was reversed following a 14-day recovery period during which ganitumab was cleared (half-life $=3-4$ days). No changes in erythrocytes or platelets were observed in mice treated with ganitumab (Fig. 3B).

To investigate the mechanisms involved in neutrophil depletion, we determined the effect of ganitumab on neutrophil induction with mGCSF. As expected, neutrophil levels increased (five- to eightfold) after mGCSF administration, with a moderate decline over a 3-week period with

Published by Bioscientifica Ltd. 
A

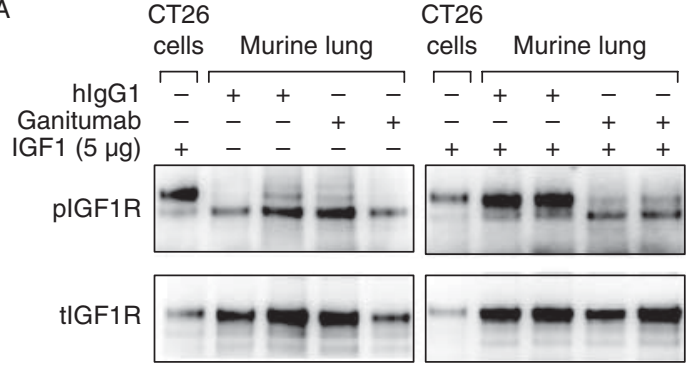

B

$\mathrm{hlgG1}++++++\ldots$

Ganitumab - $--_{-}--_{+}++++$

IGF1 - $-\quad+++-\ldots-+++$
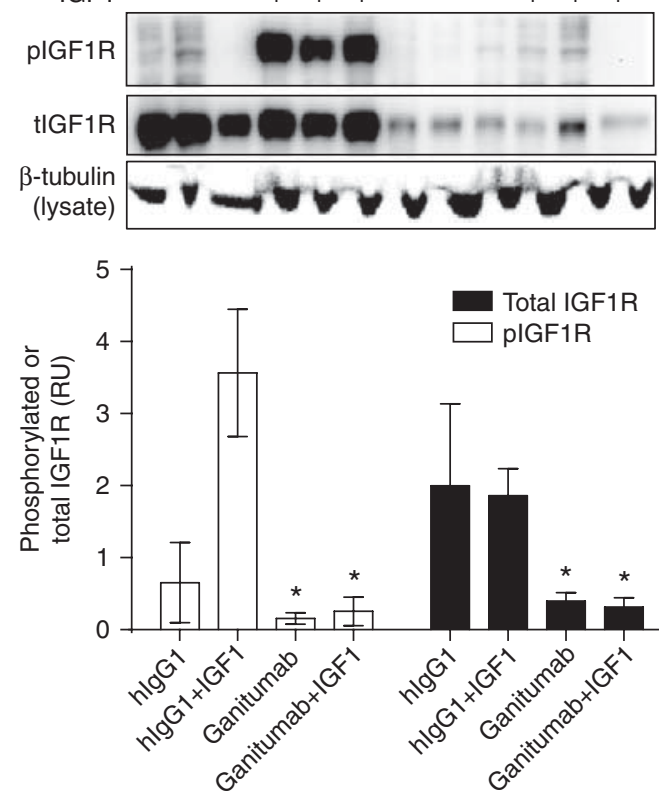

Figure 2

Inhibition of mIGF1R activation by ganitumab in vivo. (A) (Left panel) Ganitumab inhibited IGF1-induced activation of mIGF1R in murine lungs. Each lane represents an individual mouse treated once with $1 \mathrm{mg} /$ dose of ganitumab or hlgG1 for $6 \mathrm{~h}$ ( $n=2$ per group). In vitro cultures of CT26 cells were used as positive control for mIGF1R phosphorylation status. (Right panel) Densitometric analysis of IGF1R activation from the image on the left. Bars represent mean of the band intensity \pm s.D. Values were normalized to total IGF1R levels from CT26-positive controls. Significant inhibition of pIGF1R was observed in ganitumab-treated mice receiving IGF1 challenge ( $\left.{ }^{*} P<0.001\right)$. (B) Ganitumab significantly inhibited

repeated dosing. Pretreatment with ganitumab inhibited the increase in neutrophils by $75 \%(P<0.01)$ (Fig. 3C).

\section{Ganitumab causes impaired glucose tolerance in male mice}

Male mice were chosen to perform glucose-uptake experiments since they showed significantly greater reductions in glucose uptake than females when
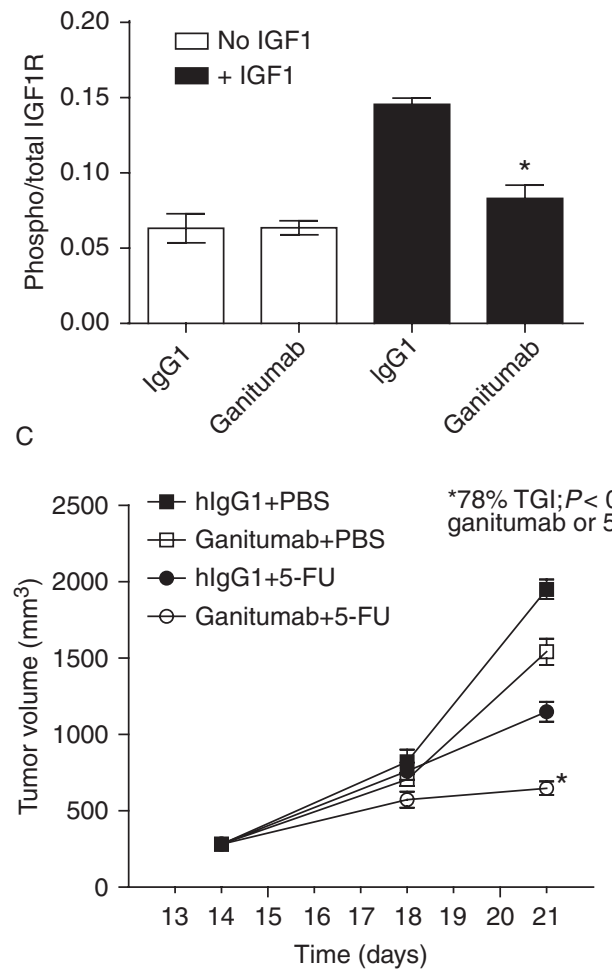

IGF1-induced mIGF1R activation in CT26 colon carcinoma tumors. Each lane of the blot represents an individual mouse treated once with $1 \mathrm{mg} / \mathrm{dose}$ of ganitumab or hlgG1 for $6 \mathrm{~h}$ ( $n=3$ per group). The bar chart shows the amount of phosphorylated and total IGF1R; data are shown as the mean \pm s.D. (* $P<0.05$ ganitumab vs hlgG1). pIGF1R, phosphorylated IGF1R; $R U$, relative units. (C) Efficacy of ganitumab in combination with 5-flurouracil in the CT26 model. CT26 xenografts were randomly divided into four groups ( $n=10)$ : i) hlgG1 + PBS, ii) ganitumab + PBS, iii) hlgG1 + 5-Flurouracil and iv) ganitumab +5 -flurouracil. Data are shown as mean tumor volume \pm s.E.M.

expression of IGF1R was lowered by gene deletion (Holzenberger et al. 2003). The effect of ganitumab on glucose uptake in naïve male athymic nude mice was determined after a glucose challenge $(2 \mathrm{~g} / \mathrm{kg})$ in pretreated animals. Ganitumab-pretreated mice had significantly higher serum glucose levels than hIgG1-pretreated mice (Fig. 4A). The maximum difference was observed at $30 \mathrm{~min}$, when ganitumab-treated mice had a $40 \%$ higher blood glucose levels than hIgG1-treated mice $(P=0.004)$. 

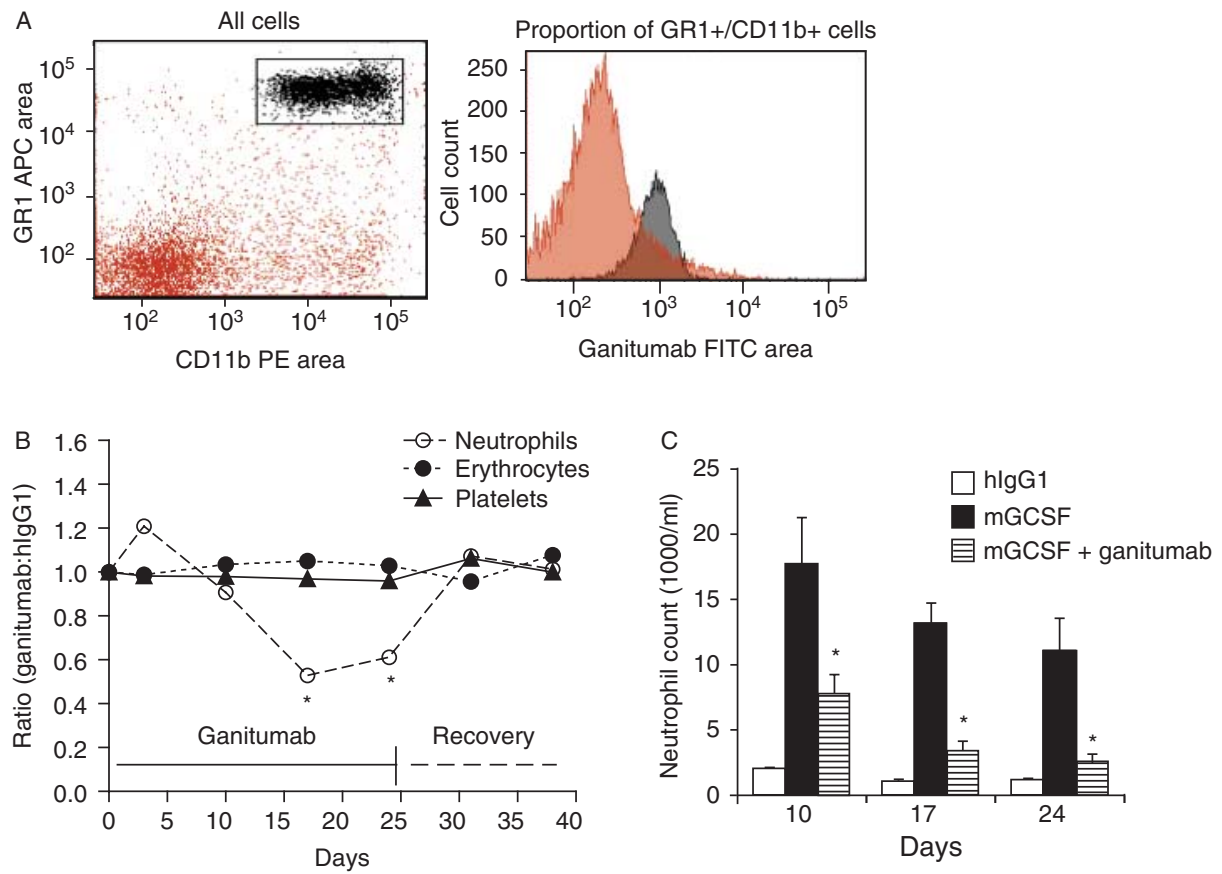

\section{Figure 3}

Effects of ganitumab on murine peripheral neutrophils. (A) Ganitumab detected mIGF1R on the surface of murine $(G R 1+/ C D 11 b+)$ peripheral blood cells using FACS analysis. The boxed area (gray) in the left panel shows the GR1 +/CD11b + cells. The right panel shows that most GR1+/ $\mathrm{CD} 11 \mathrm{~b}+$ cells (smaller gray peak) are also ganitumab positive. The orange data points represent negative cells. (B) Ganitumab significantly decreased the number of peripheral neutrophils in naïve female athymic mice.

\section{Ganitumab inhibits weight gain in athymic female nude mice}

The phenotypes of mice that carry $I g f 1 r$ and $I g f 1$ gene disruptions suggest that receptor blockade with ganitumab should inhibit increases in body weight gain (Yakar et al. 2005). Athymic nude mice were chosen to study the effects of ganitumab on weight gain to minimize immune responses against ganitumab, and females because the effect of IGF1R deficiency in female mice on longevity was more pronounced than in male mice (Holzenberger et al. 2003). Statistically significant inhibition $(\sim 50 \%, P<0.02)$ of body weight gain was observed in mice treated with $300 \mu \mathrm{g} / \mathrm{dose}$ of ganitumab twice per week by i.p. injection (Fig. 4B).

\section{Ganitumab increases serum levels of mIGF1, mIGFPB3 and $\mathrm{mGh}$}

The genetic analysis of endocrine IGF1 signaling in mice indicates that IGF1R regulates the serum IGF1 levels through inhibition of pituitary Gh release (Yakar et al. 2001). Thus, treatment of mice with ganitumab should

The ratio of the number of neutrophils in the ganitumab-treated group to the number of neutrophils in the hlgG1-treated group is shown on the indicated days. Significant differences were measured between day 17 or day 24 and day 3 or day $38(* P<0.01)$. Mice were dosed with $300 \mu \mathrm{g}$ ganitumab twice per week ( $n=8$ per group). (C) Ganitumab significantly inhibited the increase in peripheral blood neutrophils induced by mGCSF $\left({ }^{*} P<0.01 ; n=5\right)$. Data are shown as the mean \pm s.E.M.

result in elevated levels of serum mIGF1 and mGh. Indeed, statistically significant increases in the levels of mGh, mIGF1 and mIGFBP3 $\left({ }^{\star} P=0.048,{ }^{\dagger} P<0.0001\right.$ and $\left.{ }^{\ddagger} P<0.0001\right)$ were observed in ganitumab-treated mice vs hIgG1-treated mice on day 30 (Fig. 4C). Statistically significant increases in the levels of mIGFBP3 and $\mathrm{mGh}$ $(P<0.037, P<0.01$ ) were also observed on day 19 (data not shown). No measurable changes in mIGFBP1, mIGFBP2, mALS, glucose or insulin levels were obtained in any of the groups (data not shown). A significant direct correlation $\left(r^{2}=0.7, P<0.0001\right)$ between mIGF1 levels and mIGFBP3 levels was observed in ganitumab-treated mice; no correlation was observed in hIgG1-treated mice (Fig. 4D).

\section{Discussion}

Several anti-IGF1R MABs have been described in the scientific literature (Kull et al. 1983, Soos et al. 1992, Xiong et al. 1992, Li et al. 1993, Burtrum et al. 2003, Maloney et al. 2003, Cohen et al. 2005). However, to our knowledge, no data have been published that convincingly demonstrate that these antibodies physically and 

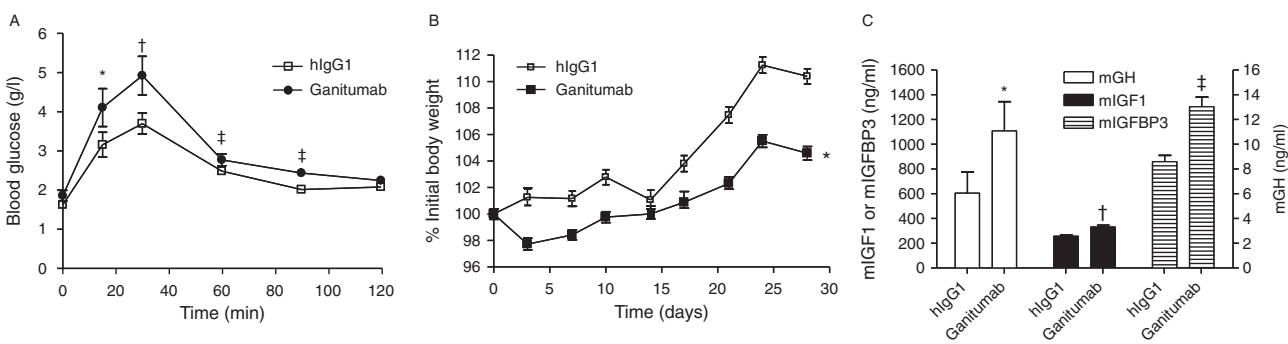

D

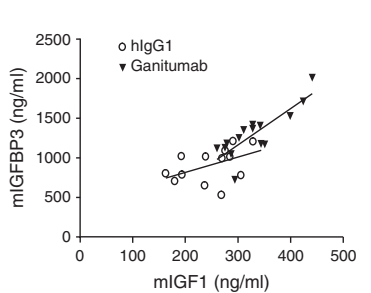

\section{Figure 4}

Physiological changes induced by ganitumab treatment. (A) Sensitization of male mice to glucose challenge $(2 \mathrm{~g} / \mathrm{kg})$ by pretreatment with ganitumab (300 $\mu \mathrm{g} /$ dose, twice per week, $n=5)$. Significant differences in blood glucose levels were observed at 15, 30,60 and 90 min post glucose challenge ( ${ }^{*} P<0.05,{ }^{\dagger} P<0.004,{ }^{\ddagger} P<0.02$ ). (B) Effect of ganitumab on body weight gain in naïve mice. Ganitumab at $300 \mu \mathrm{g} / \mathrm{dose}$ inhibited body weight gain when compared with control hlgG1 in naïve, 7-week-old, female athymic mice $(n=10)$. Weight gain was significantly different in the

functionally interact with mIGF1R. In this study, we have demonstrated that ganitumab recognized mIGF1R and inhibited its interaction with IGF1 and IGF2. Ganitumab also inhibited the activation of mIGF1R in the normal murine lung and established murine tumors. The inhibition of mIGF1R by ganitumab enhanced the cytotoxic activity of 5-flurouracil against the murine colorectal carcinoma model CT26. The cross-reactivity of ganitumab to mIGF1R is a unique characteristic of this molecule that allowed us to pharmacologically examine the effects of IGF1R inhibition on mouse physiology.

The phenotypic changes in nude mice treated with ganitumab observed in the present study were similar to the changes observed in the genetic manipulation of the GH-IGF1 axis through $I g f 1 r$ - and Igf1-targeted gene disruption (Holzenberger et al. 2003, Yakar et al. 2005). The inhibition of weight gain was comparable to the phenotype of the Igf1 $r^{(+/-)}$mice (Holzenberger et al. 2003) and liver-specific Als (Als knockout (ALSKO)) or Igf $1+A l s$ (LID+ALSKO) gene disruption (Yakar et al. 2005). Ganitumab appeared to be highly effective at inhibiting weight gain $(\sim 50 \%$ inhibition) during the treatment period in naïve mice. The lack of a more severe effect on body weight as a result of ganitumab treatment when compared with targeted homozygous deletion of $I g f 1$ or $I g f 1 r$ was probably due to the age of the animals at the time when treatment was started. In contrast to the genetic experiments where mice were exposed to IGF1 or IGF1R inhibition early in their development, treatment with ganitumab did not begin until weeks 4 through 7 and proceeded for 30 days. At this age, the average mouse body weight is $\sim 20 \mathrm{~g}$, and body weight gain is limited to a further $10-20 \%$. ganitumab-treated groups compared with the control group ( $\left.{ }^{*} P=0.028\right)$. (C) Ganitumab vs hlgG1 significantly increased serum levels of $\mathrm{mGH}$, mIGF1 and mIGFBP3 on day $30\left({ }^{\star} P=0.048,{ }^{\dagger} P<0.0001\right.$ and ${ }^{\ddagger} P<0.0001$ respectively). Data are from two experiments with a mean of 15 mice per group \pm s.D. (D) There was a significant, direct correlation $\left(r^{2}=0.7\right.$, $P<0.0001$ ) between the levels of mIGF1 and mIGFBP3 in individual ganitumab-treated mice after 30 days of treatment.

Given the effect of ganitumab on body weight, it was not surprising that ganitumab treatment led to alterations in levels of circulating GH and IGF1. Elevation of levels of pituitary Gh and/or IGF1 has been consistently observed in response to genetic inhibition of IGF1R signaling in $I g f 1 r^{(+/-)}$animals (Holzenberger et al. 2003), and in mice where circulating IGF1 levels were reduced by whole-animal (Liu \& LeRoith 1999) and liver-specific Igf1 gene disruption (Sjogren et al. 1999, Naranjo et al. 2002). Based on these genetic data, it has been hypothesized that there is a negative feedback loop in the pituitary whereby Gh release is suppressed through IGF1R signaling driven by circulating total IGF1 (Fig. 6). The pituitary Gh excess in $I g f 1 r^{(+/-)}$mice was associated with a $20-30 \%$ increase in circulating IGF1 (Holzenberger et al. 2003); we observed a similar effect when IGF1R was inhibited by ganitumab. Thus, it is likely that synthesis of IGF1 in the liver was stimulated by the excess Gh produced when pituitary IGF1R signaling was inhibited by ganitumab, thereby resulting in the serum IGF1 concentration changes observed in the treated mice. Importantly, our data show that the pituitary feedback occurs in a rapid, tightly regulated fashion.

In ganitumab-treated mice, the levels of circulating IGF1 and IGFBP3 produced by the liver appeared to be highly correlated, even though these proteins are produced in different cells (Le Roith et al. 2001). The loss of hepatic IGF1 synthesis in LID and LID + ALSKO mice was associated with a corresponding decrease in serum IGFBP3 (Sjogren et al. 1999, Naranjo et al. 2002). The genetic data and our pharmacological data with respect to IGFBP3 are most easily reconciled if IGF1R signaling has no direct role in regulating circulating IGFBP3 levels in mice.

Published by Bioscientifica Ltd. 
We propose that in well-fed mice, accumulation of IGFBP3 in circulation requires assembly into a complex with IGF1 (and ALS), while excess IGFBP3 is eliminated by a rapid clearance mechanism. Thus, in the mouse, circulating IGFBP3 levels are dependent on the total IGF1 concentration. This mechanism is consistent with the observation that no change in $I g f b p 3$ mRNA levels was detected in LID and LID + ALSKO mice on normal diets (Naranjo et al. 2002).

The modest impairment in glucose uptake and metabolism that we observed in ganitumab-treated mice is similar to what was observed in mice in which IGF1R activity had been genetically reduced (Holzenberger $e t$ al. 2003). Basal glucose levels were normal in ganitumabtreated mice, but their ability to respond to glucose challenge was significantly compromised when compared with controls. The underlying mechanism may be related to Gh-mediated insulin resistance that had been characterized previously in LID and LID ALSKO mice (Yakar et al. 2001). However, it is also possible that ganitumab induced glucose intolerance through its inhibitory effect on IGF1R in pancreatic $\beta$-islet cells (Kulkarni 2002) or on IGF1R-IR hybrids in peripheral tissues (Pandini et al. 2002). Our results provide further support for the concept that IGF1R signaling contributes to the regulation of blood glucose and is consistent with early observations of hyperglycemia in clinical trials of IGF1R inhibitors (Rodon et al. 2008).

The mild and reversible deficiency in myelopoiesis associated with ganitumab was also seen in LID mice (Welniak et al. 2004) where, similar to the effects of ganitumab, splenic myeloid progenitors were reduced by about $50 \%$, while all other hematologic parameters (including $B$ and T cells) were unaffected. The mechanism by which IGF1R blockade results in neutrophil depletion is not yet clear but may involve blockade of progenitor differentiation as described previously in cells that do not express IRS1 (Valentinis et al. 2000). Interestingly, ganitumab inhibited the increase in peripheral neutrophils induced by mGCSF suggesting a requirement for IGF1R signaling in progenitor differentiation or mobilization. Clinical data also demonstrated a reduction in neutrophil counts in some patients with cancer who received ganitumab as monotherapy (Tap et al. 2012). Our rodent studies might provide a suitable model to better understand the role of IGF1R in neutrophil differentiation and survival.

The trough serum ganitumab concentration required to achieve 50\% inhibition of BxPC-3 and MiaPaCa2 pancreatic carcinoma xenograft models $\left(\mathrm{EC}_{50}=3.05 \mu \mathrm{g} / \mathrm{ml}\right)($ Beltran et al. 2009) was tenfold higher than the $\mathrm{IC}_{50}$ for inhibition of mIGF1R activation in vitro
(Fig. 1C). Pharmacodynamic assays using murine lung tissue and murine CT26 colon carcinoma tumors showed that ganitumab blocked ligand binding to IGF1R in both tissue types but may downregulate IGF1R more efficiently in tumor cells. In vivo IGF1R downregulation was also observed previously in human tumor xenografts treated with ganitumab (Beltran et al. 2011). The exact mechanisms causing the differences in receptor downregulation between the two tissue types are unknown at this time but may involve differences in antibody exposure, endosomal/lysosomal machinery or local immune infiltrates that drive antibody-receptor crosslinking internalization and degradation.

In summary, we have shown that treatment of mice with ganitumab, a fully human MAB that is active against both human and murine IGF1R, led to a number of rapid physiological changes predicted for a pharmacological inhibitor with IGF1R activity. Treatment not only reproduced phenotypic phenomena in mouse models with targeted IGF axis disruption, but also predicted physiological and pharmacological changes in patients treated with ganitumab monotherapy in the clinic. Further clinical and preclinical analyses of these and other changes using ganitumab may identify useful biomarkers to optimize the development and utilization of IGF1Rantagonistic agents in the clinic.

\section{Declaration of interest}

G M, P J B, E C, P M, Y-A C, R K and R R are Amgen, Inc. employees and own Amgen, Inc. stock. F J C was an employee of Amgen, Inc. and owns Amgen, Inc. stock. D H and $\mathrm{P} C$ received grant support from Amgen, Inc.

\section{Funding}

This study was sponsored by Amgen, Inc. Additional grant support was provided by the National Institute on Aging (NIA 1P01AG034906).

\section{Acknowledgements}

We thank Grace Chung, Larry Daugherty and Keith Kelley for assistance with flow cytometry, Sylvia Copon for assistance with the ADVIA120 Hematology System, Robert Ortiz for assistance with the pharmacokinetic analysis, Barbara Felder for assistance with immunohistochemistry, Renato Baserga for critical review of the manuscript and Kathryn Boorer (Amgen, Inc.) for editorial assistance.

\section{References}

Anzo M, Cobb LJ, Hwang DL, Mehta H, Said JW, Yakar S, LeRoith D \& Cohen P 2008 Targeted deletion of hepatic Igf1 in TRAMP mice leads to dramatic alterations in the circulating insulin-like growth factor axis

Published by Bioscientifica Ltd. 
but does not reduce tumor progression. Cancer Research 68 3342-3349. (doi:10.1158/0008-5472.CAN-07-3165)

Baker J, Liu JP, Robertson EJ \& Efstratiadis A 1993 Role of insulin-like growth factors in embryonic and postnatal growth. Cell 75 73-82. (doi:10.1016/0092-8674(93)90680-O)

Baserga R, Hongo A, Rubini M, Prisco M \& Valentinis B 1997 The IGF-I receptor in cell growth, transformation and apoptosis. Biochimica et Biophysica Acta 1332 F105-F126.

Bass J, Kurose T, Pashmforoush M \& Steiner DF 1996 Fusion of insulin receptor ectodomains to immunoglobulin constant domains reproduces high-affinity insulin binding in vitro. Journal of Biological Chemistry 271 19367-19375. (doi:10.1074/jbc.271.32.19367)

Beltran PJ, Mitchell P, Chung YA, Cajulis E, Lu J, Belmontes B, Ho J, Tsai MM, Zhu M, Vonderfecht S et al. 2009 AMG 479, a fully human anti-insulin-like growth factor receptor type I monoclonal antibody, inhibits the growth and survival of pancreatic carcinoma cells. Molecular Cancer Therapeutics 8 1095-1105. (doi:10.1158/1535-7163. MCT-08-1171)

Beltran PJ, Chung YA, Moody G, Mitchell P, Cajulis E, Vonderfecht S, Kendall R, Radinsky R \& Calzone FJ 2011 Efficacy of ganitumab (AMG 479), alone and in combination with rapamycin, in Ewing's and osteogenic sarcoma models. Journal of Pharmacology and Experimental Therapeutics 337 644-654. (doi:10.1124/jpet.110. 178400)

Burtrum D, Zhu Z, Lu D, Anderson DM, Prewett M, Pereira DS, Bassi R, Abdullah R, Hooper AT, Koo H et al. 2003 A fully human monoclonal antibody to the insulin-like growth factor I receptor blocks liganddependent signaling and inhibits human tumor growth in vivo. Cancer Research 63 8912-8921.

Calzone FJ, Cajulis E, Chung YA, Tsai MM, Mitchell P, Lu J, Chen C, Sun J, Radinsky R, Kendall R et al. 2013 Epitope-specific mechanisms of IGF1R inhibition by ganitumab. PLOS ONE $\mathbf{8}$ e55135. (doi:10.1371/journal. pone.0055135)

Cohen BD, Baker DA, Soderstrom C, Tkalcevic G, Rossi AM, Miller PE, Tengowski MW, Wang F, Gualberto A, Beebe JS et al. 2005 Combination therapy enhances the inhibition of tumor growth with the fully human anti-type 1 insulin-like growth factor receptor monoclonal antibody CP-751,871. Clinical Cancer Research 11 2063-2073. (doi:10.1158/ 1078-0432.CCR-04-1070)

Frasca F, Pandini G, Scalia P, Sciacca L, Mineo R, Costantino A, Goldfine ID, Belfiore A \& Vigneri R 1999 Insulin receptor isoform A, a newly recognized, high-affinity insulin-like growth factor II receptor in fetal and cancer cells. Molecular and Cellular Biology 19 3278-3288.

Gallagher EJ \& LeRoith D 2011 Minireview: IGF, insulin, and cancer. Endocrinology 152 2546-2551. (doi:10.1210/en.2011-0231)

Guha M 2013 Anticancer IGF1R classes take more knocks. Nature Reviews. Drug Discovery 12 250. (doi:10.1038/nrd3992)

Heidegger I, Pircher A, Klocker H \& Massoner P 2011 Targeting the insulinlike growth factor network in cancer therapy. Cancer Biology \& Therapy 11 701-707. (doi:10.4161/cbt.11.8.14689)

Holzenberger M, Dupont J, Ducos B, Leneuve P, Geloen A, Even PC, Cervera P \& Le Bouc Y 2003 IGF-1 receptor regulates lifespan and resistance to oxidative stress in mice. Nature 421 182-187. (doi:10.1038/nature01298)

Hwang DL, Lee PD \& Cohen P 2008 Quantitative ontogeny of murine insulin-like growth factor (IGF)-I, IGF-binding protein-3 and the IGF-related acid-labile subunit. Growth Hormone \& IGF Research 18 65-74. (doi:10.1016/j.ghir.2007.07.007)

Kulkarni RN 2002 Receptors for insulin and insulin-like growth factor-1 and insulin receptor substrate- 1 mediate pathways that regulate islet function. Biochemical Society Transactions 30 317-322. (doi:10.1042/ BST0300317)

Kull FC Jr, Jacobs S, Su YF, Svoboda ME, Van Wyk JJ \& Cuatrecasas P 1983 Monoclonal antibodies to receptors for insulin and somatomedin-C. Journal of Biological Chemistry 258 6561-6566.
Lee C, Safdie FM, Raffaghello L, Wei M, Madia F, Parrella E, Hwang D, Cohen P, Bianchi G \& Longo VD 2010 Reduced levels of IGF-I mediate differential protection of normal and cancer cells in response to fasting and improve chemotherapeutic index. Cancer Research 70 1564-1572. (doi:10.1158/0008-5472.CAN-09-3228)

Le Roith D, Scavo L \& Butler A 2001 What is the role of circulating IGF-I? Trends in Endocrinology and Metabolism 12 48-52. (doi:10.1016/ S1043-2760(00)00349-0)

Li SL, Kato J, Paz IB, Kasuya J \& Fujita-Yamaguchi Y 1993 Two new monoclonal antibodies against the alpha subunit of the human insulin-like growth factor-I receptor. Biochemical and Biophysical Research Communications 196 92-98. (doi:10.1006/bbrc. 1993.2220)

Liu JL \& LeRoith D 1999 Insulin-like growth factor I is essential for postnatal growth in response to growth hormone. Endocrinology 140 5178-5184. (doi:10.1210/endo.140.11.7151)

Maloney EK, McLaughlin JL, Dagdigian NE, Garrett LM, Connors KM, Zhou XM, Blattler WA, Chittenden T \& Singh R 2003 An antiinsulin-like growth factor I receptor antibody that is a potent inhibitor of cancer cell proliferation. Cancer Research 63 5073-5083.

Naranjo WM, Yakar S, Sanchez-Gomez M, Perez AU, Setser J \& LeRoith D 2002 Protein calorie restriction affects nonhepatic IGF-I production and the lymphoid system: studies using the liver-specific IGF-I gene-deleted mouse model. Endocrinology 143 2233-2241. (doi:10.1210/endo.143.6.8852)

Pandini G, Frasca F, Mineo R, Sciacca L, Vigneri R \& Belfiore A 2002 Insulin/insulin-like growth factor I hybrid receptors have different biological characteristics depending on the insulin receptor isoform involved. Journal of Biological Chemistry 277 39684-39695. (doi:10.1074/jbc.M202766200)

Pollak M 2012 The insulin and insulin-like growth factor receptor family in neoplasia: an update. Nature Reviews. Cancer 12 159-169.

Rodon J, DeSantos V, Ferry RJ Jr \& Kurzrock R 2008 Early drug development of inhibitors of the insulin-like growth factor-I receptor pathway: lessons from the first clinical trials. Molecular Cancer Therapeutics 7 2575-2588. (doi:10.1158/1535-7163.MCT-08-0265)

Sjogren K, Liu JL, Blad K, Skrtic S, Vidal O, Wallenius V, LeRoith D, Tornell J, Isaksson OG, Jansson JO et al. 1999 Liver-derived insulin-like growth factor I (IGF-I) is the principal source of IGF-I in blood but is not required for postnatal body growth in mice. PNAS 96 7088-7092. (doi:10.1073/ pnas.96.12.7088)

Soos MA, Field CE, Lammers R, Ullrich A, Zhang B, Roth RA, Andersen AS, Kjeldsen T \& Siddle K 1992 A panel of monoclonal antibodies for the type I insulin-like growth factor receptor. Epitope mapping, effects on ligand binding, and biological activity. Journal of Biological Chemistry 267 12955-12963.

Tap WD, Demetri G, Barnette P, Desai J, Kavan P, Tozer R, Benedetto PW, Friberg G, Deng H, McCaffery I et al. 2012 Phase II study of ganitumab, a fully human anti-type-1 insulin-like growth factor receptor antibody, in patients with metastatic ewing family tumors or desmoplastic small round cell tumors. Journal of Clinical Oncology 30 1849-1856. (doi:10.1200/JCO.2011.37.2359)

Valentinis B, Navarro M, Zanocco-Marani T, Edmonds P, McCormick J, Morrione A, Sacchi A, Romano G, Reiss K \& Baserga R 2000 Insulin receptor substrate-1, p70S6K, and cell size in transformation and differentiation of hemopoietic cells. Journal of Biological Chemistry 275 25451-25459. (doi:10.1074/jbc.M002271200)

Welniak LA, Karas M, Yakar S, Anver MR, Murphy WJ \& LeRoith D 2004 Effects of organ-specific loss of insulin-like growth factor-I production on murine hematopoiesis. Biology of Blood and Marrow Transplantation 10 32-39. (doi:10.1016/j.bbmt.2003.09.008)

Xiong L, Kasuya J, Li SL, Kato J \& Fujita-Yamaguchi Y 1992 Growthstimulatory monoclonal antibodies against human insulin-like growth factor I receptor. PNAS 89 5356-5360. (doi:10.1073/pnas.89.12. 5356) 
Yakar S, Liu JL, Stannard B, Butler A, Accili D, Sauer B \& LeRoith D 1999 Normal growth and development in the absence of hepatic insulin-like growth factor I. PNAS 96 7324-7329. (doi:10.1073/pnas. 96.13.7324)

Yakar S, Liu JL, Fernandez AM, Wu Y, Schally AV, Frystyk J, Chernausek SD, Mejia W \& Le Roith D 2001 Liver-specific igf-1 gene deletion leads to muscle insulin insensitivity. Diabetes 50 1110-1118. (doi:10.2337/ diabetes.50.5.1110)
Yakar S, Pennisi P, Kim CH, Zhao H, Toyoshima Y, Gavrilova O \& LeRoith D 2005 Studies involving the GH-IGF axis: lessons from IGF-I and IGF-I receptor gene targeting mouse models. Journal of Endocrinological Investigation 28(Suppl 5) 19-22.

Yuen JS \& Macaulay VM 2008 Targeting the type 1 insulin-like growth factor receptor as a treatment for cancer. Expert Opinion on Therapeutic Targets 12 589-603. (doi:10.1517/14728222. 12.5.589)

Received in final form 2 February 2014

Accepted 3 February 2014

Accepted Preprint published online 3 February 2014
Published by Bioscientifica Ltd. 